\title{
Management of metastatic prostate cancer: recent advances, clinical perspectives and future prospects
}

\author{
N. Joseph ${ }^{1}$ and A. Choudhury ${ }^{2}$ \\ ${ }^{1}$ District General Hospital Chillaw, Sri Lanka. \\ ${ }^{2}$ Christie NHS Foundation Trust, Manchester and Faculty of Biology, Medicine and Health, \\ University of Manchester, Manchester, UK.
}

\section{Introduction}

Nearly two-thirds of all patients with prostate cancer in Sri Lanka present with systemic metastases (1). Since the seminal discovery of its effect by Huggins and Hodges in 1941, androgen deprivation therapy (ADT) has remained the bedrock in the management of metastatic prostate cancer (2). There has been a surge in the development of new therapeutic options in metastatic prostate cancer and this article reviews some of these recent advances from the perspective of clinical practice in Sri Lanka.

\section{Conventional management of metastatic prostate cancer}

\section{Androgen deprivation therapy}

Medical castration with gonadotropin-releasing hormone $(\mathrm{GnRH})$ agonists has replaced orchiectomy as the principal mode of androgen deprivation in developed countries (3). GnRH agonists work by long term inhibition of luteinizing hormone (LH) release from the anterior pituitary gland. Paradoxically, the initial response of the anterior pituitary gland to $\mathrm{GnRH}$ agonists is to increase the release of $\mathrm{LH}$ which results in a testosterone surge (4). Consequently, a short course of antiandrogens is prescribed, commencing two weeks prior to initiation of GnRH agonists to guard against a clinical flare caused by this temporary surge in testosterone levels (4).

A meta-analysis of several randomized clinical trials of GnRH agonist therapy in advanced prostate cancer demonstrated equivalent survival with orchiectomy (5). However, a recent retrospective analysis of over 3000 patients in the Surveillance, Epidemiology, and End Results (SEER) database demonstrated increased risk of fractures, peripheral arterial disease and cardiacrelated complications in patients treated with $\mathrm{GnRH}$ agonists in comparison to those undergoing bilateral orchiectomy (6).

\section{Alternatives to androgen deprivation}

Monotherapy with the non-steroidal anti-androgen bicalutamide was investigated with a view to avoiding the troublesome side effects of castration. Bicalutamide monotherapy at a dose of $150 \mathrm{mg}$ results in less fatigue, loss of libido and fewer vasomotor symptoms than GnRH analogues, but causes breast enlargement and tenderness (7). While it remains an option in patients who decline either medical or surgical castration, a Cochrane review revealed an inferior survival with antiandrogen monotherapy (8).

Another approach to ameliorate the adverse effects of permanent castration is intermittent androgen deprivation (IAD) therapy with $\mathrm{GnRH}$ agonists. Using this strategy, patients with a favourable response (defined as prostate specific antigen (PSA) less than $4 \mathrm{mg} / \mathrm{dl}$ within 9 months of initiation of ADT), have their treatment discontinued with close PSA surveillance (9). ADT is reinitiated if PSA rises to a pre-defined cut-off of around 10-20 mg/dl (9). A recent review of seven randomized trials concluded that neither superiority nor non-inferiority of IAD could be established in comparison to continuous androgen deprivation (CAD) (10). In the SWOG 9346 phase III non-inferiority trial, which was the largest study comparing IAD versus $\mathrm{CAD}$ in metastatic prostate cancer, IAD failed to achieve the pre-defined criteria of non-inferiority. In contrast, there was a non-significant trend towards better survival in the CAD arm (11).

\section{Complete androgen blockade (CAB)}

Another strategy in the initial management of metastatic prostate cancer is the addition of a non-steroidal antiandrogen to ADT with a view to suppressing the production of testosterone by non-testicular sources such as the adrenal gland (12). Two large American trials testing the benefit of $\mathrm{CAB}$ reported conflicting results. In patients treated with the GnRH agonist 
leuprolide, the addition of flutamide resulted in a significant improvement in survival (13). However, in a second trial in patients treated with bilateral orchiectomy, flutamide failed to demonstrate superiority (14). A meta-analysis by the Prostate Cancer Trialists' Collaborative Group revealed a 3\% improvement in 5 year survival in favour of $\mathrm{CAB}$ with the addition of a non-steroidal anti-antrogen, either nilutamide or flutamide, and outcome was inferior with the addition of cyproterone acetate (15). Given the modest gain in survival, $\mathrm{CAB}$ is not recommended due to adverse effects on quality of life as well as questions relating to its cost-effectiveness (3).

\section{Castration resistant prostate cancer (CRPC)}

ADT in metastatic prostate cancer results in a response rate of nearly $80 \%$, with a median biochemical progression free survival (bPFS) of around 18-24 months (16). However all tumours will eventually progress to a state of castration resistance. The European Asso-ciation of Urology (EAU) defines CRPC as biochemical or radiological progression in the presence of castrate levels of testosterone $(<50 \mathrm{mcg} / \mathrm{dl})$ (3). Biochemical progression is defined as a PSA rise of over $50 \%$ from nadir with an absolute value $>2 \mathrm{mg} / \mathrm{dl}$ while radiological progression is defined as the presence of two or more new bone lesions or a new soft tissue lesion (3).

\section{Secondary hormonal manipulation}

Historically, CRPC was treated with secondary hormonal manipulation with bicalutamide, low dose steroids and diethylstilbestrol, all of which have some symptomatic benefit but no improvement in overall survival (OS) (3).

The addition of an anti-androgen, most commonly bicalutamide to ADT, has limited success in CRPC, with a median bPFS of around 4 months (17). In addition, bicalutamide can function as a partial agonist driving disease progression, and discontinuation of this drug may elicit a biochemical response in some patients, known as the anti-androgen withdrawal response (18).

Low dose steroids, either $10 \mathrm{mg}$ of prednisolone or 500 micrograms of dexamethasone improves quality of life and pain control with biochemical response rates of $30 \%-50 \%$ and bPFS of 4-12 months in single series reports $(19,20)$. In fact, in many clinical trials testing newer systemic options, low dose steroids was prescribed in the control arm.

Diethylstilbesterol (DES) is an oestrogen which has been used since 1940 in metastatic prostate cancer. In randomized controlled clinical trials concerns were raised over increased mortality from cardiovascular and thromboembolic events when used at a dose of $5 \mathrm{mg}$ (21). The cardiovascular adverse effects were significantly less with a lower dose of DES of $1 \mathrm{mg}$ and efficacy was similar (21). A retrospective review of CRPC patients treated with $1 \mathrm{mg}$ of DES with $75 \mathrm{mg}$ of aspirin and breast bud radiotherapy at the Royal Marsden Hospital revealed a biochemical response rate of $28 \%$ and bPFS of 4.6 months, but nearly $10 \%$ of patients had thromboembolic complications (22).

\section{Chemotherapy}

In a landmark trial by Tannock et al, mitoxantrone became the first chemotherapeutic agent to demonstrate symptomatic benefit in CRPC (23). Although no survival gain was demonstrated, its use became standard of care in CRPC. Subsequently, the SWOG 99-19 and TAX 327 trials established the role of docetaxel by demonstrating a 2-3 months gain in OS in comparison to mitoxantrone in patients with symptomatic disease $(24,25)$. Docetaxel was prescribed at a dose of $75 \mathrm{mg}$ per square meter of body surface area every three weeks with $5 \mathrm{mg}$ of prednisolone twice daily, upto a maximum of 10 cycles (24). Heralding a new dawn for systemic therapy in CRPC, docetaxel was the first agent to demonstrate a benefit in OS in CRPC $(24,25)$.

\section{Recent advances in management of hormone sensitive prostate cancer}

\section{Upfront chemotherapy with docetaxel}

As mentioned previously, the use of palliative chemotherapy was initially limited to patients with symptomatic castration resistant disease, where the benefit in terms of symptom and disease control would justify enduring the considerable toxicity of systemic chemotherapy. The rationale for the use of upfront chemotherapy stems from the premise that, if the same proportional reduction in hazards holds true in hormonesensitive disease as it does in castration resistant disease, this would translate to a substantially higher absolute gain in overall survival.

Three randomized trials tested this paradigm changing hypothesis. The French GETUG-AFU-15 trial did not demonstrate any improvement in survival with the use of upfront docetaxel (26). However the CHAARTED trial demonstrated a substantial gain in survival (Median OS 57.6 months versus 44 months) with use of upfront docetaxel, particularly in patients with high-volume disease (27). In this trial high volume disease was defined as the presence of visceral metastases or 4 or more bone deposits with at least one outside the spine or pelvis (27). Subsequently the UK STAMPEDE trial, which was the largest of the three studies, also 
demonstrated a significant benefit with use of docetaxel but did no subgroup analysis was performed based on disease burden (Median OS 45 months versus 60 months) (28). As a result, there is a divergence of opinion on the benefit of docetaxel in low volume hormone sensitive metastatic prostate cancer.

Unlike in CRPC the number of cycles of docetaxel in hormone sensitive disease is limited to $6(27,28)$. Furthermore, the use of low-dose prednisolone in the hormone sensitive setting is questionable. In the CHAARTED trial standard steroid premedication was used without daily low-dose prednisolone (27). However in the STAMPEDE Trial docetaxel was coprescribed with low-dose prednisolone (28).

\section{Bisphosphonates}

The MRC PR05 trial in the UK, randomized patients with metastatic prostate cancer treated with ADT to sodium clodronate or placebo and reported a significant improvement in overall survival (median OS 37 months versus 28 months) (29). However the trial failed to reach significance in its primary endpoint of boneprogression free survival, although there was a clear trend in favour of the active treatment arm (29). Recently, the STAMPEDE trial reported no benefit with use of upfront zoledronic acid with ADT (28). The MRC PR05 trial was conducted prior to the advent of docetaxel in castration-resistant disease, raising the question whether better systemic therapies obscure any survival gain with upfront use of bisphosphonates (29). Interestingly the median OS in standard of care arm in the STAMPEDE trial was substantially higher than in the MRC PR05 trial (45 months versus 28 months) $(28,29)$.

\section{GnRH antagonists}

Apart from GnRH agonists, degarelix a GnRH antagonist is licensed for use in metastatic prostate cancer. Unlike GnRH analogues, degarelix results in faster testosterone suppression, without a surge and risk of clinical flare. A randomized phase III trial demonstrated non-inferiority with GnRH agonists in terms of achieving castrate levels of testosterone (30). An additional analysis demonstrated better PSA responses and freedom from biochemical relapse, however more evidence is needed to conclusively establish superior efficacy of GnRH antagonists over GnRH agonists $(31,32)$.

\section{Upfront novel anti-androgen therapy}

The success of docetaxel in this setting gave credence to the theory of proportional hazard reduction leading to larger absolute gains in survival if a therapeutic option is used earlier than later in the course of a disease. As a result trials were conducted to test the benefit of the novel anti-androgens abiraterone and enzalutamide in hormone sensitive prostate cancer, along with a newer anti-androgen apalutamide which has a lower incidence of seizures and nervous system toxicity compared to enzalutamide $(62,63,64,65)$. The results of the LATITUDE trial published concurrently with that of the STAMPEDE trial, demonstrated a clear benefit in favour of abiraterone in combination with ADT compared to ADT alone $(62,63)$. The recently published ENZAMET trial also showed superior OS with use of enzalutamide and ADT in this setting, as did the newer anti-androgen apalutamide $(64,65)$.

\section{Radiotherapy to the prostate gland}

A recent hypothesis postulates that the primary tumour continues to drive progression of metastatic disease (54). Retrospective data supports such a premise and several mechanisms have been described such as, continued shedding of tumour emboli to systemic sites, migration of stromal cells and the immunomodulatory effects of the primary tumour $(54,55)$. Two randomized trials tested the benefit of radiotherapy to the prostate gland in the hormone sensitive metastatic disease and produced conflicting results. While in the Dutch HORRAD there was no benefit with RT to the prostate gland, the STAMPEDE trial revealed a benefit in patients with low-volume disease $(66,67)$.

Table 1 summarizes the results of recent phase III trials in hormone sensitive prostate cancer.

\section{Recent advances in management of castration- resistant prostate cancer after treatment with docetaxel}

\section{Cabazitaxel}

Cabazitaxel is a novel tubulin-binding taxane which has demonstrated pre-clinical efficacy in cell lines refractory to docetaxel and paclitaxel (33). The multi-centre international phase III TROPIC trial randomized patients progressing after docetaxel to cabazitaxel or mitoxantrone (33). Visceral metastases was present in $25 \%$ of patients and $45 \%$ had significant cancer related pain. Most patients in this trial had progressed within 3 months of treatment with docetaxel including $30 \%$ who progressed during chemotherapy. The study reported a 2.4 months improvement in median OS with a $30 \%$ reduction in the risk of death (33). Median progression free survival was 6 weeks. Nearly $45 \%$ of patients who progressed within 3 months of treatment with docetaxel demonstrated a gain in survival, confirming its efficacy in patients refractory to docetaxel. However there was a significant increase in grade 3 or more neutropaenia $(82 \%$ vs $58 \%)$ in the cabazitaxel arm. 
Table 1. Summarized results of recent phase III clinical trials in hormone-sensitive prostate cancer

\begin{tabular}{|c|c|c|c|c|}
\hline \multirow{2}{*}{ Trial name } & \multirow{2}{*}{$\begin{array}{c}\text { Experimental } \\
\text { treatment }\end{array}$} & \multicolumn{2}{|c|}{ Outcome } & \multirow{2}{*}{ p value } \\
\hline & & $\begin{array}{l}\text { Hazard ratio } \\
(95 \% \text { confidence } \\
\text { interval })\end{array}$ & $\begin{array}{l}\text { Median OS difference } \\
\text { (in months) }\end{array}$ & \\
\hline GETUG-AFU 15 (26) & Docetaxel & $\begin{array}{l}1.01 \\
(0.75-1.36)\end{array}$ & 4.7 (58.9 vs 54.2$)$ & $\mathrm{p}=0.44$ \\
\hline CHAARTED (27) & Docetaxel & $\begin{array}{l}0.6 \\
(0.47-0.8)\end{array}$ & $13.6(57.6$ vs 44$)$ & $\mathrm{p}<0.001$ \\
\hline STAMPEDE (28) & Docetaxel & $\begin{array}{l}0.76 \\
(0.62-0.92)\end{array}$ & 15 (60 vs 45$)$ & $\mathrm{p}=0.005$ \\
\hline STAMPEDE (28) & Zoledronic acid & $\begin{array}{l}0.93 \\
(0.77-1.11)\end{array}$ & $1(46$ vs 45$)$ & $\mathrm{p}=0.45$ \\
\hline STAMPEDE (62) & Abiraterone & $\begin{array}{l}0.63 \\
(0.52-0.76)\end{array}$ & 3 year OS $83 \%$ vs $76 \%^{*}$ & $\mathrm{p}<0.001$ \\
\hline LATITUDE (63) & Abiraterone & $\begin{array}{l}0.62 \\
(0.51-0.76)\end{array}$ & 3 year OS $66 \%$ vs $49 \%^{*}$ & $\mathrm{p}<0.001$ \\
\hline ENZAMET (64) & Enzalutamide & $\begin{array}{l}0.67 \\
(0.52-0.86)\end{array}$ & 3 year OS $80 \%$ vs $72 \%^{*}$ & $\mathrm{p}=0.002$ \\
\hline TITAN (65) & Apalutamide & $\begin{array}{l}0.67 \\
(0.51-0.89)\end{array}$ & 2 year OS $82 \%$ vs $73 \%^{*}$ & $\mathrm{p}=0.005$ \\
\hline HORRAD (66) & RT to prostate & $\begin{array}{l}0.9 \\
(0.7-1.14)\end{array}$ & $2(45 \mathrm{Vs} 43)$ & $\mathrm{p}=0.4$ \\
\hline STAMPEDE $^{* *}(67)$ & RT to prostate & $\begin{array}{l}0.68 \\
(0.52-0.9)\end{array}$ & 3 year OS $81 \%$ vs $73 \%$ & $\mathrm{p}=0.007$ \\
\hline
\end{tabular}

ADT - Androgen deprivation therapy. OS - overall survival. RT - Radiotherapy

* Median OS not reached.

** Low volume disease sub-group.

\section{Abiraterone}

One of the principal molecular mechanisms driving castration-resistance is increased concentrations of intra-tumoural androgens caused by upregulation of androgen biosynthesis enzymes (34). Cytochrome P450 c17 (CYP17) is a critical enzyme involved in androgen synthesis and the antifungal ketoconazole which inhibits this enzyme was previously used in CRPC although no survival advantage could be demonstrated (35). Abiraterone acetate was developed as a novel selective inhibitor of CYP17, which suppresses synthesis of testosterone by the adrenal gland, testis and prostate cancer cells (36). In 2011, de Bono et al reported the results of the landmark phase III COU-
AA-301 trial which randomized CRPC patients treated with docetaxel to abiraterone and prednisolone or placebo and prednisolone, demonstrating a 3.9 months improvement in OS (14.8 months versus 10.9 months) (37). Abiraterone causes an increase in mineralocorticoid levels resulting in hypokalemia, fluid retention and hypertension, which is ameliorated with the use of low-dose prednisolone (37). Grade 4 liver toxicity was reported early in the trial but there were no new cases after a subsequent protocol amendment mandated more rigorous assessment of liver function with suspension of treatment in the event of grade 3 elevations in transaminases (37). 


\section{Enzalutamide}

Apart from an increased synthesis of intra-tumoural androgens, overexpression of the androgren receptor is another mechanism of tumour progression in castration resistant disease (38). Enzalutamide is antiandrogen agent that inhibits nuclear translocation, DNA binding, and coactivator recruitment of the androgen receptor (39). The randomized double-blind phase III AFFIRM trial which tested its efficacy in the postdocetaxel setting reported a 4.8 month improvement in median OS (18.4 months versus 13.6 months) (40). Unlike abiraterone it does not require co-prescription of steroids and has less toxic effects on the liver (40). However it causes more fatigue and is contraindicated in patients with epilepsy or an increased predisposition to develop seizures such as brain metastases, stroke, brain injury and alcoholism (40).

\section{Recent advances in management of castration- resistant prostate cancer prior to treatment with docetaxel}

\section{Sipuleucel-T}

Cancer-induced immune incompetence caused by secretion of cytokines such as Transforming Growth Factor beta leading to suppression of cytotoxic T cells, helper $\mathrm{T}$ cells and natural killer cells has been demonstrated in castration resistant prostate cancer (43). Sipuleucel-T is an active cellular immunotherapy consisting of autologous peripheral-blood mononuclear cells, including antigen-presenting cells (APCs), that have been activated ex vivo with a recombinant fusion protein (PA2024) (44). PA2024 consists of a prostate antigen, prostatic acid phosphatase, that is fused to granulocyte-macrophage colony-stimulating factor (44). The phase III IMPACT trial demonstrated a 4 months absolute improvement in survival in favour of the Sipuleucal-T arm in comparison to placebo (45). Only asymptomatic patients were included in the trial and patients treated with two or more lines of chemotherapy were excluded. Moreover, only $15 \%$ of patients were treated with docetaxel and nearly $75 \%$ of patients in this trial had a Gleason score of 7 or less (45). Sipuleucel-T was the first immunotherapeutic agent to demonstrate effectiveness in CRPC (45).

\section{Anti-androgens}

Both abiraterone and enzalutamide have demonstrated a modest but significant improvement in survival in CRPC patients not treated with docetaxel. Importantly, trials in this setting were restricted to asymptomatic or mildly symptomatic patients in whom docetaxel was not clinically indicated. In the PREVAIL study of enzalutamide in CRPC patients not treated with docetaxel, there was a $23 \%$ reduction in the risk of death and the absolute gain in median overall survival was 2.2 months (32.4 versus 30.2 months) (46). Abiraterone was tested in a similar population in the COU-AA-302 trial and demonstrated significantly improved outcomes in its favour (Hazard Ratio 0.75 for OS, Median OS 34.7 months versus 30.3 months) (47). Both abiraterone and enzalutamide was prescribed until radiological or clinical progression. Following these landmark trials enzalutamide and abiraterone were licensed for use in asymptomatic or mildly symptomatic CRPC patients with good performance status prior to the use of docetaxel.

An interesting phase II randomized trials compared low dose abiraterone $(250 \mathrm{mg}$ ) taken with food as opposed to the standard dose $1000 \mathrm{mg}$ taken fasting and showed that there was no difference in PSA metrics, although abiraterone concentrations were higher in the standard dose arm (68). The findings were sufficiently provocative for this low-dose regimen to be included in the NCCN guidelines due to substantial gains in cost-effectiveness (69).

Table 2 summarizes the results of recent phase III trials in castration resistant prostate cancer.

\section{Use of bone-targeted agents in castration resistant prostate cancer}

Nearly $90 \%$ of patients with metastatic prostate cancer have skeletal deposits and a majority of patients have no evidence of extra-skeletal disease (59). Therefore, controlling metastatic disease in the bone holds the potential to lead to symptomatic benefit and improved survival.

\section{Radium-223}

Radium-223 dicholoride (radium-223) is a bone-seeking calcium mimetic that binds to areas of newly formed bone stroma especially in osteoblastic metastases and emits alpha particles of short range resulting in a localized cytotoxic effect (41). Due its short path it has limited effects on healthy bone marrow (41). The ALSYMPCA trial randomized patients with symptomatic bone metastases who had received, were not eligible to receive, or declined docetaxel, to either radium-223 or placebo (42). The presence of visceral metastases was an exclusion criteria (42). The trial reported a $30 \%$ reduction in the risk of death with a 3.6 month absolute improvement in survival (42). There was minimal haematological toxicity and a slight increase in nausea, vomiting and diarrhoea due to its route of elimination (42). 
Table 2. Summarized results of recent phase III clinical trials in castration resistant prostate cancer

\begin{tabular}{|l|l|l|c|c|}
\hline \multirow{2}{*}{ Trial name } & \multirow{2}{*}{$\begin{array}{c}\text { Experimental } \\
\text { treatment }\end{array}$} & \multicolumn{2}{|c|}{ Outcome } & p value \\
\cline { 3 - 4 } & & $\begin{array}{l}\text { Hazard ratio } \\
\text { (95\% confidence } \\
\text { interval) }\end{array}$ & $\begin{array}{c}\text { Median OS difference } \\
\text { (in months) }\end{array}$ & \\
\hline TROPIC & $\begin{array}{l}\text { Cabazitaxel } \\
\text { (post-docetaxel) }\end{array}$ & $0.70(0.59-0.83)$ & $2.4(15.1$ vs 12.7$)$ & $\mathrm{p}<0.0001$ \\
\hline AFFIRM & $\begin{array}{l}\text { Enzalutamide } \\
\text { (post-docetaxel) }\end{array}$ & $0.63(0.53-0.75)$ & $4.8(18.4$ vs 13.6$)$ & $\mathrm{p}<0.001$ \\
\hline COU-AA-301 & $\begin{array}{l}\text { Abiraterone } \\
\text { (post-docetaxel) }\end{array}$ & $0.65(0.54-0.77)$ & $4.6(15.8$ vs 11.2$)$ & $\mathrm{p}<0.001$ \\
\hline ALSYMPCA & Radium-223 & $0.70(0.55-0.88)$ & $3.6(14.9$ vs 11.3$)$ & $\mathrm{p}=0.002$ \\
\hline IMPACT & $\begin{array}{l}\text { Sipuleucel-T } \\
\text { (pre-docetaxel) }\end{array}$ & $0.78(0.61-0.98)$ & $4.1(25.8$ vs 21.7$)$ & $\mathrm{p}=0.03$ \\
\hline PREVAIL & $\begin{array}{l}\text { Enzalutamide } \\
\text { (pre-docetaxel) }\end{array}$ & $0.71(0.6-0.84)$ & $2.2(32.4$ vs 30.2$)$ & $\mathrm{p}<0.001$ \\
\hline COU-AA-302 & $\begin{array}{l}\text { Abiraterone } \\
\text { (pre-docetaxel) }\end{array}$ & $0.81(0.7-0.93)$ & $4.4(34.7$ vs 30.3) & $\mathrm{p}=0.0033$ \\
\hline
\end{tabular}

\section{Bisphosphonates and denosumab}

The use of bisphosphonates in CRPC is the subject of much controversy. A phase III trial demonstrated a relative reduction of $25 \%$ in skeletal related events $(33 \%$ versus $44 \%$ ) with use of zoledronic acid, with no difference in overall or progression free survival (48). Denosumab is a fully human monoclonal antibody which inactivates the receptor activator of nuclear factor- $\kappa \mathrm{B}$ ligand resulting in inhibition of osteoclast mediated bone resorption (49). A phase III trial demonstrated prolongation of time to first skeletal event (20.7 months versus 17.1 months) with the use of denosumab over zoledronic acid with no significant difference in bPFS or OS (49).

\section{Clinical perspectives}

\section{Hormone sensitive prostate cancer}

Given the significant cost and potential cardiovascular adverse effects of GnRH analogues, we recommend bilateral orchiectomy as the modality of choice to achieve androgen deprivation in our patients. Even though intermittent androgen deprivation and bicalutamide monotherapy are alternatives to continuous androgen deprivation, there are valid concerns about an inferior outcome with such approaches. Complete androgen blockade in patients treated with surgical castration failed to demonstrate superiority in a phase III trial and with its significant adverse effects on quality of life it should not be offered as standard practice.

The magnitude of benefit with the use of upfront docetaxel demonstrated in the CHAARTED and STAMPEDE trials is one the largest absolute gains in any metastatic cancer in recent times. Upfront docetaxel is now recommended for use in all patients with metastatic prostate cancer in the European guidelines (3). In the CHAARTED trial the benefit of docetaxel was predominantly confined to patients with high volume disease (27). However, in the STAMPEDE trial, which is the largest trial in metastatic prostate cancer, no subgroup analysis of disease performed was performed and the benefit of upfront docetaxel was evident for the whole population (28). In any event, in the absence of PSA screening, most of our patients with metastatic disease are likely to have high volume disease.

In the light of these paradigm-changing results, all patients with metastatic prostate cancer should be 
referred to a clinical oncologist after orchiectomy for an evaluation on fitness for upfront chemotherapy with docetaxel. We recommend a maximum of six cycles of docetaxel to all newly diagnosed patients with metastatic prostate cancer who have undergone androgen deprivation and fit enough to receive chemotherapy. Even in patients with borderline performance status, it is more prudent to offer upfront docetaxel in the hormone-sensitive phase, as performance status is likely to deteriorate with disease progression and chemotherapy may not be feasible in the castrationresistant setting. Given the divergence in the co-prescription of low dose prednisolone in the CHAARTED and STAMPEDE trials, no firm recommendation can be made about its use.

While there is some controversy due to the conflicting results in the clinical trials of radiotherapy to the prostate gland, we recommend offering this treatment to patients with low volume disease since the data in the STAMPEDE trial is highly robust. Varying definitions of high burden disease have been proposed but we prefer the definition used in the STAMPEDE trial -4 or more bone metastases (with at least one outside the pelvis and vertebral bodies) and/or the presence visceral metastasis (67). Another bone of contention is the dichotomy of low-volume and high volume disease in this disease group. While it is axiomatic that patients with higher burden of disease have a poorer outcome, whether such a characterization is predictive of benefit with treatment is uncertain for systemic treatment option. The STAMEDE trial will conduct a post-hoc sub-group analysis of the benefit of docetaxel by disease volume later this year which should settle the controversy in relation to chemotherapy. At present we recommend offering docetaxel to all patients with hormone sensitive metastatic prostate cancer regardless of disease burden.

Although in the light of the controversy in relation to volume of disease, trials of these newer anti-androgens performed a sub-group analyses which showed that the benefit in OS gain was independent of disease burden, the results of these studies were published after upfront docetaxel had already become standard of care $(62,63,64,65)$. As such there is no evidence to suggest that novel anti-androgens are superior to docetaxel in this setting $(62,63,64,65)$. In addition, the financial toxicity of treating with these expensive agents for a prolonged duration in the hormone sensitive disease setting also merits careful consideration. As such, we recommend against treating patients with hormone sensitive metastatic prostate cancer with novel antiandrogen until more data is available.

The STAMPEDE trial has demonstrated no benefit with the use of zoledronic acid and it should not be routinely offered to patients with hormone-sensitive disease.

Key recommendations and practice points in hormone sensitive prostate cancer are listed in Box 1.

\section{Box 1}

\section{Key recommendations and practice points in hormone-sensitive prostate cancer}

1. Bilateral orchiectomy is the preferred option for androgen deprivation.

2. Intermittent androgen deprivation and bicalutamide monotherapy is not recommended due to concerns about inferior outcome.

3. Complete androgen blockade is not recommended due to insufficient evidence of benefit after orchiectomy and adverse effect on quality of life.

4. All patients should be referred to a clinical oncologist after initiation of androgen deprivation for an evaluation to determine fitness for upfront docetaxel.

5. Upfront docetaxel with androgen deprivation is recommended to all patients fit to receive chemotherapy.

6. Radiotherapy to the prostate gland is recommended in patients with low disease burden.

7. The novel anti-androgens abiraterone, enzalutamide and apalutamide are not recommended due to uncertainty of benefit in the context of upfront docetaxel and concerns of financial toxicity.

8. Upfront zoledronic acid is not recommended due to absence of any survival benefit. 


\section{Castration resistant prostate cancer}

A number of therapeutic options are now available for use in CRPC. While individual trials have demonstrated efficacy for a single modality, there is scant evidence on how best to select and sequence these options. Therefore the management of CRPC needs to be approached by applying first principles and sound clinical judgement. Important factors to consider in decisionmaking are performance status including comorbidities, disease burden and response to previous therapies.

Clinical trials in CRPC were restricted to patients with a Eastern Cooperative Oncology Group (ECOG) performance status of 0-2, and consequently none of the newer systemic modalities such as docetaxel, enzalutamide, abiraterone, cabazitaxel and radium-223 can be recommended for patients with a ECOG performance status of 3 or more. In these patients lowdose steroids and DES at a dose of $1 \mathrm{mg}$ (co-prescribed with $75 \mathrm{mg}$ of aspirin) may offer symptomatic benefit.

Trials of abiraterone and enzalutamide in CRPC before docetaxel, were restricted to clinically asymptomatic or minimally symptomatic patients with good performance status, in whom docetaxel was not clinically indicated. For patients with symptomatic disease in whom chemotherapy is indicated, there is no randomized trial evidence to support the use of either abiraterone or enzalutamide prior to the use of docetaxel. Consequently, for patients with symptomatic castrationresistant disease, we recommend docetaxel as the treatment of choice, rather than a novel anti-androgen. The European guidelines support such an approach, recommending docetaxel as the preferred option in this setting, but also offer enzalutamide or abiraterone to patients declining to receive chemotherapy (3).

In CRPC patients with asymptomatic or minimally symptomatic disease, enzalutamide or abiraterone could be offered to patients with a good performance status, if funding is available. These patients have a relatively good survival, as demonstrated by the median survival duration of nearly 30 months in the control arms of the PREVAIL and COU-AA-302 trials. The median duration of treatment was nearly 16-17 months, since antiandrogens are prescribed until radiological or clinical progression. The use of these expensive agents for such long periods has considerable financial implications and would prove to be prohibitively expensive in the local setting where substantial funding restrictions apply.

In patients with disease progression after treatment with docetaxel, we recommend the use of either abiraterone or enzalutamide. While the same cost-effectiveness issues are relevant even in the use of novel anti- androgens after chemotherapy, the duration of treatment is considerably shorter in this setting.

There is no evidence of superiority of either drug when used before or after chemotherapy. As such it is not possible to recommend one novel anti-androgen over another, and the choice of which agent to use would depend upon a consideration of adverse effects. Enzalutamide does not require the use of concomitant steroids and requires less intensive monitoring of liver function than abiraterone. However, the incidence of fatigue is significantly higher in patients treated with enzalutamide and it is contraindicated in patients with epilepsy or a predisposition to seizures. There is significant cross-resistance between enzalutamide and abiraterone primarily due to mutations in the androgen receptor (50) and there is no evidence to support the sequential use of these agents. For patients in whom abiraterone is offered we strongly recommend using the lower dosage of $250 \mathrm{mg}$ with food, given its equivalence in terms of PSA metrics and the substantial benefit in terms of cost reduction.

Radium-223 is not licensed for use in Sri Lanka. Recently it was approved by NICE for use in CRPC patients with symptomatic bone metastases and no visceral deposits, who have been treated with docetaxel. It is unlikely to be cost-effective in our country even in this group of patients (51). Zoledronic acid has a modest reduction in the incidence of skeletal related events but has no impact on overall or progression free survival. Therefore, even in patients with symptomatic bone metastases, we recommend that its use be restricted to CRPC patients who have been treated with docetaxel (and a novel anti-androgen if funding is available).

Despite being the first agent to demonstrate a survival gain in CRPC patients treated with docetaxel, the place of cabazitaxel in the era of novel anti-androgens is less clear. NICE approval was recently granted for its use in CRPC patients treated with docetaxel and who have not received abiraterone, enzalutamide or radium-223 (52). There are no prospective data to guide the optimal sequencing of cabazitaxel, but given its heavy cost and considerable toxicity its place in the local setting is very limited. As mentioned previously, cabazitaxel is effective in patients with resistance to docetaxel and, therefore patients who progress rapidly or have a poor response to androgen deprivation may benefit from this drug than from a novel anti-androgen. We would recommend considering cabazitaxel in CRPC patients with good performance status who progress during or within three months of docetaxel and who have also had a poor response to androgen deprivation. If funding is not available for either cabazitaxel or a novel anti-androgen, mitoxantrone would be an acceptable option in patients fit enough to receive second-line chemotherapy. 
With use of docetaxel in hormone-sensitive prostate cancer, its place in CRPC raises new questions. However, $14-28 \%$ of patients who received upfront docetaxel in clinical trials were also treated with docetaxel in the castration-resistant setting (26-28). Cabazitaxel was used less frequently in the GETUGAFU-15 and STAMPEDE trials, but nearly $24 \%$ of patients in the docetaxel arm went on to receive cabazitaxel in the CHAARTED trial (26-28). Rechallenge with docetaxel or cabazitaxel are reasonable options in CRPC patients who have received upfront docetaxel. Cost-effectiveness needs to be factored in this situation, and we would recommend docetaxel rechallenge as the preferred treatment in the Sri Lankan setting.

Key recommendations and practice points in castrationresistant prostate cancer are listed in Box 2.

\section{Future prospects}

\section{Hormone sensitive prostate cancer}

The emerging concept of oligometastatic disease in oncology, where metastatic tumours with limited deposits may have a prognostically better outlook than those with widespread secondaries, is increasingly gaining currency (60). Oligometastatic tumours may have the potential for prolonged survival or even cure with intensive therapy. In prostate cancer, treatment of oligometastatic disease with stereotactic body radiation therapy, where high doses of radiotherapy are delivered to tumour deposits with tight margins, has demonstrated impressive results in some retrospective studies (61). More evidence from randomized clinical trials are needed before this paradigm could find acceptance in the clinical setting.

\section{Box 2}

\section{Key recommendations and practice points in castration-resistant prostate cancer}

1. Abiraterone and enzalutamide are equivalent options in asymptomatic or minimally symptomatic patients with good performance status, in whom docetaxel is not indicated ${ }^{* *}$.

2. Initiation of bicalutamide and subsequent withdrawal at disease progression are reasonable options in asymptomatic or minimally symptomatic patients with biochemical disease progression.

3. Docetaxel is the treatment of choice in symptomatic patients fit to receive chemotherapy.

4. Abiraterone and enzalutamide are equivalent options in patients progressing after treatment with docetaxel*. $^{*}$.

5. In patients offered abiraterone, strongly consider offering a dose of $250 \mathrm{mg}$ with food as opposed to $1000 \mathrm{mg}$ on an empty stomach.

6. Cabazitaxel is recommended in patients progressing during or within three months of docetaxel and who have also had a short duration of response to androgen deprivation ${ }^{* *}$.

7. Radium-223 is recommended in good performance status patients progressing after docetaxel with no visceral deposits and symptomatic bone disease ${ }^{* *}$.

8. Mitoxantrone could be offered to suitable patients with symptomatic disease progression after docetaxel (and a novel anti-androgen if funding is available).

9. Zoledronic acid should be restricted to patients with predominantly bone metastases and symptomatic disease progression after treatment with docetaxel (and a novel anti-androgen if funding is available).

10. Low-dose steroids and low dose diethylstilbestrol with aspirin are options in patients with poor performance status.

* Subject to funding availability.

${ }^{* *}$ Unlikely to be cost-effective in the Sri Lankan setting. 


\section{Castration resistant prostate cancer}

There are no prospective data to guide optimal sequencing of therapeutic options in CRPC and randomized clinical trials are needed to address this unmet clinical need. In addition there are no prospectively validated predictive biomarkers to guide treatment choices in a disease where several alternatives with clinical equipoise exist. Androgen receptor variant 7 (ARv7) expression in circulating-tumour cells has shown considerable promise in predicting a poor response with anti-androgens, however it needs further validation (50).

A recent phase II trial demonstrated benefit with use of the poly(adenosine diphosphate [ADP]-ribose) polymerase (PARP) inhibitor olaparib in tumours with defects in DNA repair genes such as BRCA2 (56). Mutations in these genes are also predictive of benefit with platinum agents in other tumours, and if replicated in CRPC it would prove to be a more cost-effective than olaparib (57). Another agent that has shown efficacy in single arm studies is metformin, whose anti-neoplastic action is not fully characterized but believed to be related to its ability to inhibit the PI3K-AKT-mTOR pathway (58).

With the success of Sipuleucel-T in CRPC, interest is also focussed on many immunotherapeutic strategies, but predictive biomarkers are needed prior to clinical application $(44,45)$.

\section{Conclusion}

Recent advances have revolutionized the management of prostate cancer both in its hormone-sensitive and refractory phases. Individual clinical trials have been elegant in design, successfully establishing the benefit of individual agents. However, there is a dearth of evidence to guide selection and sequencing of these options. Despite impressive results in clinical trials, metastatic prostate cancer remains incurable and it is imperative that the potential for prolongation of survival offered by any therapeutic modality be balanced against its adverse effects on quality of life.

\section{References}

1. Abeygunasekera AM, Wijayarathna SN, de Silva K et al. Clinicopathological characteristics and primary treatment of prostate cancer in a urology unit of Sri Lanka. J Cancer Res Ther. 2015; 11(4): 780-5.

2. Huggins C, Stevens RE, Hodges CV. Studies on prostatic cancer. II. The effects of castration on advanced carcinoma of the prostate cancer. Arch Surg 1941; 43: 209-23.
3. Mottet N, Bellmunt J, Briers E et al. EAU-ESTROSIOG Guidelines on Prostate Cancer 2016 Available at http://uroweb.org/wp-content/uploads/EAUGuidelines-Prostate-Cancer-2016.pdf

4. Thompson IM. Flare Associated with LHRHAgonist Therapy Rev Urol. 2001; 3(Suppl 3): S10-S14.

5. Seidenfeld J, Samson DJ, Hasselblad V, et al. Singletherapy androgen suppression in men with advanced prostate cancer: a systematic review and meta-analysis. Ann Intern Med. 2000 Apr 4; 132(7): 566-77.

6. Sun M, Choueiri TK, Hamnvik OP, et al. Comparison of Gonadotropin-Releasing Hormone Agonists and Orchiectomy: Effects of AndrogenDeprivation Therapy. JAMA Oncol. 2016; 2(4): 500-7.

7. Smith MR, Goode M, Zietman AL et al. Bicalutamide monotherapy versus leuprolide monotherapy for prostate cancer: effects on bone mineral density and body composition. J Clin Oncol. 2004; 22(13): 2546-53.

8. Kunath F, Grobe HR, Rücker G, et al. Non-steroidal antiandrogen monotherapy compared with luteinising hormone-releasing hormone agonists or surgical castration monotherapy for advanced prostate cancer. Cochrane Database Syst Rev. 2014; 30(6): CD009266.

9. Rashid MH, Chaudhary UB. Intermittent androgen deprivation therapy for prostate cancer. Oncologist. 2004; 9(3): 295-301.

10. Hussain M, Tangen C, Higano $C$ et al. Evaluating Intermittent Androgen-Deprivation Therapy Phase III Clinical Trials: The Devil Is in the Details. J Clin Oncol. 2016 Jan 20; 34(3): 280-5.

11. Hussain M, Goldman B, Tangen C et al. Prostatespecific antigen progression predicts overall survival in patients with metastatic prostate cancer: data from Southwest Oncology Group Trials 9346 (Intergroup Study 0162) and 9916. J Clin Oncol. 2009 May 20; 27(15): 2450-6.

12. Chodak GW. A critical review of maximal androgen blockade for advanced prostate cancer. Rev Urol. 2004; 6 Suppl 8: S18-23

13. Crawford ED, Eisenberger MA, McLeod DG, et al. A controlled trial of leuprolide with and without flutamide in prostatic carcinoma. N Engl $\mathrm{J}$ Med 1989; 321: 419-24.

14. Eisenberger MA1, Blumenstein BA, Crawford ED et al. Bilateral orchiectomy with or without flutamide 
for metastatic prostate cancer. N Engl J Med. 1998 Oct 8; 339(15): 1036-42.

15. Prostate Cancer Trialists' Collaborative Group. Maximum androgen blockade in advanced prostate cancer: an overview of the randomised trials. Lancet. 2000; 355: 1491-8.

16. Harris WP, Mostaghel EA, Nelson PS, Montgomery B. Androgen deprivation therapy: progress in understanding mechanisms of resistance and optimizing androgen depletion. Nature clinical practice Urology. 2009; 6(2): 76-85.

17. Kucuk O, Fisher E, Moinpour CM, et al. Phase II trial of bicalutamide in patients with advanced prostate cancer in whom conventional hormonal therapy failed: a Southwest Oncology Group study (SWOG 9235). Urology. 2001; 58(1): 53-8.

18. Paul R, Breul J. Antiandrogen withdrawal syndrome associated with prostate cancer therapies: incidence and clinical significance. Drug Saf. 2000; 23(5): 381-90.

19. Tannock I, Gospodarowicz M, Meakin W, et al. Treatment of metastatic prostatic cancer with lowdose prednisone: evaluation of pain and quality of life as pragmatic indices of response. J Clin Oncol 1989; 7: 590-7.

20. Venkitaraman R, Thomas K, Huddart RA, et al. Efficacy of low-dose dexamethasone in castrationrefractory prostate cancer. BJU Int. 2008; 101(4): 440-3.

21. Byar DP, Corle DK. Hormone therapy for prostate cancer: results of the Veterans Administration Cooperative Urological Research Group studies. NCI Monogr 1988; 46: 165-70.

22. Wilkins A, Shahidi M, Parker C, et al. Diethylstilbestrol in castration-resistant prostate cancer. BJU Int. 2012; 110(11 Pt B): E727-35.

23. Tannock IF, Osoba D, Stockler MR, et al. Chemotherapy with mitoxantrone plus prednisone or prednisone alone for symptomatic hormoneresistant prostate cancer: a Canadian randomized trial with palliative end points. J Clin Oncol. 1996; 14(6): 1756-64.

24. Tannock IF, de Wit R, Berry WR, et al. Docetaxel plus prednisone or mitoxantrone plus prednisone for advanced prostate cancer. N Engl J Med. 2004; 351(15): 1502-12.

25. Petrylak DP, Tangen CM, Hussain MH. Docetaxel and estramustine compared with mitoxantrone and prednisone for advanced refractory prostate cancer. N Engl J Med. 2004 Oct 7; 351(15): 1513-20.
26. Gravis G, Fizazi K, Joly F, et al. Androgendeprivation therapy alone or with docetaxel in noncastrate metastatic prostate cancer (GETUG-AFU 15): a randomised, open-label, phase 3 trial. Lancet Oncol. 2013;14(2): 149-58.

27. Sweeney CJ, Chen YH, Carducci M, et al. Chemohormonal therapy in metastatic hormonesensitive prostate cancer. N Engl J Med. 2015; 373(8): 737-46.

28. James ND, Sydes MR, Clarke NW, et al. Adding docetaxel and/or zoledronic acid for hormone-naive prostate cancer (STAMPEDE): survival results form an adaptive multi-arm multi-stage platform randomised controlled trial. Lancet 2016; 387 : 1163-77.

29. Dearnaley DP, Mason MD, Parmar MK, et al. Adjuvant therapy with oral sodium clodronate in locally advanced and metastatic prostate cancer: long-term overall survival results from the MRC PR04 and PR05 randomised controlled trials. Lancet Oncol. 2009; 10(9): 872-6.

30. Klotz L, Boccon-Gibod L, Shore ND, et al. The efficacy and safety of degarelix: a 12-month, comparative, randomized, open-label, parallel-group phase III study in patients with prostate cancer. BJU Int. 2008; 102(11): 1531-8.

31. Tombal B , Miller K, Boccon-Gibod L, et al. Additional analysis of the secondary end point of biochemical recurrence rate in a phase 3 trial (CS21) comparing degarelix $80 \mathrm{mg}$ versus leuprolide in prostate cancer patients segmented by baseline characteristics. Eur Urol. 2010; 57(5): 836-42.

32. Crawford ED, Tombal B, Miller K, et al. A phase III extension trial with a 1 -arm crossover from leuprolide to degarelix: comparison of gonadotropinreleasing hormone agonist and antagonist effect on prostate cancer. J Urol. 2011;186(3): 889-997.

33. de Bono JS, Oudard S, Ozguroglu M, et al. Prednisone plus cabazitaxel or mitoxantrone for metastatic castration-resistant prostate cancer progressing after docetaxel treatment: a randomised open-label trial. Lancet. 2010; 376(9747): 1147-54.

34. Montgomery RB, Mostaghel EA, Vessella R, et al. Maintenance of intratumoral androgens in metastatic prostate cancer: a mechanism for castration-resistant tumor growth. Cancer Res. 2008; 68: 4447-4454.

35. Harris KA, Weinberg V, Bok RA, et al. Low dose ketoconazole with replacement doses of hydrocortisone in patients with progressive androgen 
independent prostate cancer. J Urol. 2002;168(2): 542-5.

36. Attard G, Belldegrun AS, de Bono JS. Selective blockade of androgenic steroid synthesis by novel lyase inhibitors as a therapeutic strategy for treating metastatic prostate cancer. BJU Int. 2005; 96: 1241-6.

37. de Bono JS, Logothetis CJ, Molina A, et al. Abiraterone and increased survival in metastatic prostate cancer. N Engl J Med. 2011;3 64(21): 19952005.

38. Visakorpi T, Hyytinen E, Koivisto P, et al. In vivo amplification of the androgen receptor gene and progression of human prostate cancer. Nat Genet 1995; 9: 401-6.

39. Tran C, Ouk S, Clegg NJ, et al. Development of a second-generation antiandrogen for treatment of advanced prostate cancer. Science 2009;324:787790.

40. Scher HI, Fizazi K, Saad F, et al. Increased survival with enzalutamide in prostate cancer after chemotherapy. N Engl J Med. 2012; 367(13):118797.

41. Henriksen G, Breisto K, Bruland O, et al. Significant antitumor effect from bone-seeking, alpha-particleemitting (223)Ra demonstrated in an experimental skeletal metastases model. Cancer Res 2002; 62: 3120-5.

42. Parker C, Nilsson S, Heinrich D, et al. Alpha emitter radium-223 and survival in metastatic prostate cancer. N Engl J Med 2013; 369: 213-23.

43. Di Lorenzo G, Ferro M, Buonerba C. Sipuleucel-T $\left(\right.$ Provenge $^{\circledR}$ ) for castration-resistant prostate cancer. BJU Int. 2012; 110(2 Pt 2): E99-10.

44. Drake CG. Prostate cancer as a model for tumour immunotherapy. Nat Rev Immunol. 2010; 10(8): 580-93.

45. Kantoff PW, Higano CS, Shore ND, et al. Sipuleucel-T immunotherapy for castrationresistant prostate cancer. N Engl J Med. 2010; 363(5): 411-22.

46. Scher HI, Fizazi K, Saad F, et al. Increased survival with enzalutamide in prostate cancer after chemotherapy.N Engl J Med. 2012; 367(13): 118797.

47. Ryan CJ, Smith MR, de Bono JS, et al. Abiraterone in metastatic prostate cancer without previous chemotherapy. N Engl J Med. 2013 10; 368(2): 138-48.
48. Saad F, Gleason DM, Murray RJ, et al. A randomized, placebo-controlled trial of zoledronic acid in patients with hormone-refractory metastatic prostate carcinoma. Natl Cancer Inst. 2002; 94(19):1458-68.

49. Fizazi K, Carducci M, Smith M, et al. Denosumab versus zoledronic acid for treatment of bone metastases in men with castration-resistant prostate cancer: a randomised, double-blind study. Lancet. 2011 Mar 5;377(9768):813-22.

50. Antonarakis ES, Lu C, Wang H, et al. AR-V7 and resistance to enzalutamide and abiraterone in prostate cancer. N Engl J Med. 2014; 371: 1028-38.

51. National Institute for Health and Care Excellence (NICE). Radium-223 dichloride for treating hormone-relapsed prostate cancer with bone metastases. 27 January 2016. Available at http:// https://www.nice.org.uk/guidance/ta376/chapter/1Recommendations. Accessed 26th September 2016.

52. National Institute for Health and Care Excellence (NICE). Cabazitaxel for hormone-relapsed metastatic prostate cancer treated with docetaxel. 24 August 2016. Available at http://https:// www.nice.org.uk/guidance/ta391/chapter/1Recommendations. Accessed 26th September 2016.

53. Attard G, Sydes MR, Mason MD, et al. Combining enzalutamide with abiraterone, prednisone, and androgen deprivation therapy in the STAMPEDE trial. Eur Urol. 2014; 66(5): 799-802.

54. Weckermann D, Polzer B, Ragg T, et al. Perioperative activation of disseminated tumor cells in bone marrow of patients with prostate cancer. J Clin Oncol 2009; 27: 1549-56.

55. Parker CC, Sydes MR, Mason MD, et al. Prostate radiotherapy for men with metastatic disease: a new comparison in the Systemic Therapy in Advancing or Metastatic Prostate Cancer: Evaluation of Drug Efficacy (STAMPEDE) trial. BJU Int, 111: 69799.

56. Mateo J, Carreira S, Sandhu S et al. DNA-Repair Defects and Olaparib in Metastatic Prostate Cancer. N Engl J Med. 2015; 373(18): 1697-708.

57. Farmer H, McCabe N, Lord CJ, et al. Targeting the DNA repair defect in BRCA mutant cells as a therapeutic strategy. Nature 2005; 434: 917-21.

58. Rothermundt C, Hayoz S, Templeton AJ, et al. Metformin in chemotherapy-naive castration- 
resistant prostate cancer: a multicenter phase 2 trial (SAKK 08/09). Eur Urol. 2014; 66(3): 468-74.

59. Bubendorf L, Schöpfer A, Wagner U, et al. Metastatic patterns of prostate cancer: an autopsy study of 1,589 patients. Hum Pathol. 2000; 31(5): 578-83.

60. Hellman S, Weichselbaum RR. Oligometastases. J Clin Oncol. 1995; 13(1): 8-10.

61. Conde Moreno AJ, Ferrer Albiach C, Muelas Soria $\mathrm{R}$, et al. Oligometastases in prostate cancer: restaging stage IV cancers and new radiotherapy options. Radiat Oncol. 2014; 9: 258.

62. James ND, de Bono J, Spears MR, et al. Abiraterone for prostate cancer not previously treated with hormone therapy. N Engl J Med 2017; 377: 338-51.

63. Fizazi K, Tran N, Matsubara N et al. Abiraterone plus prednisolone in metastatic castration sensitive prostate cancer. N Engl J Med. 2017;377:352-360

64. Davis ID, Martin AJ, Stockler MR, et al. Enzalutamide with standard first-line therapy in metastatic prostate cancer. N Engl J Med 2019;381:121-131.

65. Chi KN, Agarwal N, Bjartell A, et al. Apalutamide for metastatic castration sensitive prostate cancer. N Engl J Med 2019; 381: 13-24.

66. Boevé LM, Hulshof MC, Vis AN, et al. Effect on Survival of Androgen Deprivation Therapy Alone Compared to Androgen Deprivation Therapy Combined with Concurrent Radiation Therapy to the Prostate in Patients with Primary Bone Metastatic Prostate Cancer in a Prospective Randomised Clinical Trial: Data from the HORRAD Trial. Eur Urol. 2019;75(3): 410-18.

67. Parker CC, James ND, Brawley CD, et al. Radiotherapy to the primary tumour for newly diagnosed, metastatic prostate cancer (STAMPEDE): a randomised controlled phase 3 trial. Lancet. 2018; 392(10162): 2353-66.

68. Szmulewitz RZ, Peer CJ, Ibraheem A, et al. Prospective International Randomized Phase II Study of Low-Dose Abiraterone With Food Versus Standard Dose Abiraterone In Castration-Resistant Prostate Cancer. J Clin Oncol. 2018; 36(14): 138995.

69. Mohler JL, Antonrakis ES, Armstrong AJ et al. Prostate Cancer, Version 2.2019, NCCN Clinical Practice Guidelines in Oncology. J Natl Compr Canc Netw. 2019; 17(5): 479-505 